\title{
Effect of Process Parameters on Etch Depth of Stainless-Steel Material in Photo Chemical Machining by Using Different Etchants
}

\author{
S. V. Kulkarni, A. A. Utpat, B.A. Kamble
}

\begin{abstract}
Now a days manufacture without burr and stress-free micro components Photochemical machining (PCM) is an emerging technology. To manufacture very thin, precision and complex parts in electronics, automotive and various other industries the use of non-conventional machining processes such as PCM are increasing. The first step of the process is designing a photo tool (CAD drawing) which is made by printing the drawing onto transparency paper. The investigation of Photochemical machining for Stainless Steel was analyzed at different control parameters. The control parameters are temperature and time and response parameters are etching depth and surface roughness. The study objective is to compare etching depth and roughness of Stainless-Steel (SS) material for two different etchants (Ferric chloride and Nitric acid) at different control parameters. The value of responses increases with increasing values of control parameters.
\end{abstract}

Index Terms - PCM, Polymer coating, Machining, Etching.

\section{INTRODUCTION}

The Photochemical machining process has numerous applications in creating micro-components in different industries such as automotive, electronics and mechanical engineering. The process is also known as wet etching, chemical milling etc. The photoresist used in the process has two types which are -

- Positive photoresist

- Negative photoresist

The PCM is started with designing of drawing in AutoCAD and other designing software and printing drawing on a transparency sheet. In second step the polymer solution is coated onto base metal (SS). The designed tool is kept on photoresist and exposed by using UV light by using UV light units. The photo tool drawing is transferred onto polymer coating and it will be visible after applying the developing solution. Davis P.J et al. [1] etched micro components such as microchannels etc. Allen D.M et al. [2][3] demonstrate the photochemical machining for three-dimensional applications and etched different micro-components in electronic and mechanical industries. The ferric chloride etchant characteristics were defined for different applications. o Cakir et al[4] developed a regenerated waste etchant

S. V. Kulkarni, M Tech student, SVERI's College of Engineering, Pandharpur-413304,India.

A. A. Utpat, Professor, Karmayogi Engineering College, Pandharpur-413304,India.

B.A. Kamble, Research scholar, SVERI's College of EngineeringPandharpur-413304,India treatment process for cupric chloride etching solution . Jang D.M et al. [5] created a 3D SIP process for different electronics applications. Barron et al. [6] studied the chemical reaction when light incident on positive and negative type photoresist solution. The properties of photoresist solution were analyzed. Bruzzone et al. [7] created a photochemical machining simulation model in which the effect of control parameters on responses were analyzed. Saraf et al. [8] designed a mathematical model for the photochemical machining process. Bhasme et al. [11] analysed response parameters for SS316L steel. The selection of etching is different for different engineering materials. The values of response measures are different for different materials.

The major steps involved on 3D PCM is given below

- Photo tool design

- Material selection

- Material cleaning

- Polymer coating

- Developer processing

- Etched by using etching solution

- Stripping

Misal et.al $[12,13]$ studied the surface properties of Inconel 718 and Monel material. The parametric effect was analysed at different conditions for hard material like monel and Inconel. Wangikar et al. [14] optimized brass and German silver and compared etching behaviors of both materials. Kamble et al. [15] created a 3D photochemical machining process for copper material by studying the UV light interaction with photoresist material. The innovative photo tool was designed to pass low and high intensity UV light into a transparency sheet. The main objective is to analyze effect of control parameters on resulting parameters. The effect of process parameters on an etching depth on a Stainless-Steel strip were studied by using ferric chloride and nitric acid etchants. Different researchers [16-29] have reported the microfeatures, micro channel heat sink, textured bearing, etc. fabrication using photochemical machining and also by employing laser engraving method. The parametric analysis is also reported.

\section{MATERIAL AND METHOD}

Stainless Steel material was used to study the etching behaviors at different etching solutions. It is used in many industrial applications. The selected material is cut into $30 \mathrm{~mm} \times 30 \mathrm{~mm}$ x $1 \mathrm{~mm}(\mathrm{Lx} B \times \mathrm{T})$. The PCM process starts with designing a photo tool by using different designing softwares such as AutoCAD, Catia etc. The required design is 


\section{Effect of Process Parameters on Etch Depth of Stainless-Steel Material in Photo Chemical Machining by Using Different Etchants}

nothing but the component which will be produced etching. The size and dimension of the product are given at the time preparation of drawing. The drawing is printed on to the transparency paper shown in fig 2(a) having a thickness of 80 microns. The more the thickness the less light can be transferred through it. In the next step, the Stainless-Steel plate is cut into required size and cleaned by using a thinner cleaning agent. The negative photoresist is applied onto the plate by using a dip coating method, then after the coating is dried by using a drier for 2 min to adhere the solution onto base metal. The size of the coating is about 4 to 5 microns. The quality of the etching depends on the resolution of printing. After coating the photoresist, the design is kept on to coating and it is exposed by using high intensity UV light. The 2D exposing unit shown in fig 2(b) is used to expose the coating at time $90 \mathrm{sec}$.

After exposing the base metal, the next step is development of base metal by using a developing solution. The exposed sample is dipped into a developing solution for $90 \mathrm{sec}$. After that it is rinsed into the running water. After the development process the design is visible to naked eye. In the development process soft photoresist coating is washed out and hard coating of photoresist remains on it to protect the surface from unnecessary etching. In the etching process, a developed component is dipped into selected etchants which are ferric chloride and nitric acid solution. In the etching process, the area unexposed through UV light is etched and the exposed area is unetched.

In the etching process, the area which is open to the atmosphere is etched away and the area which is covered by photoresist remains as it is. The etching setup is shown below fig.2(c). The fig. 1 shows the PCM flowchart, which explains the PCM process and its different steps.

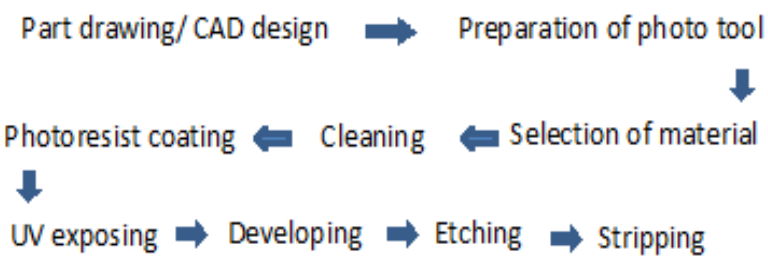

Fig.1 PCM Flowchart

The finished samples are shown in Fig 2 (d)
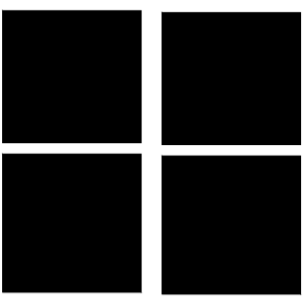

a)

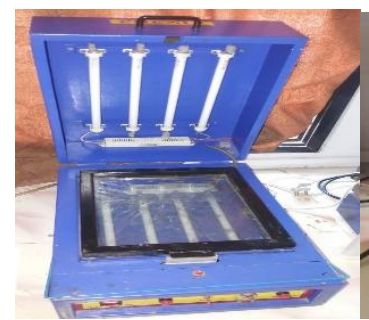

b)

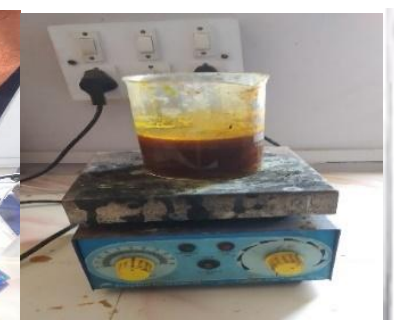

c)

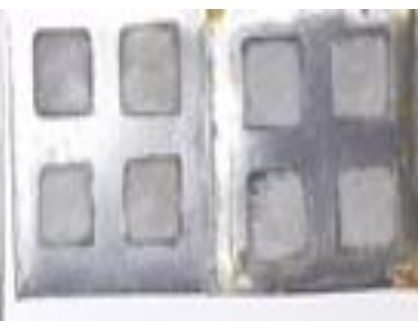

d)

Fig.2 a) photo tool b) 3D exposure unit c)3D etching unit d) finished component

\section{DESIGN OF EXPERIMENTS}

To study etching behaviors of Stainless-Steel material, the preliminary experimentation was carried out by using two different etchants ferric chloride and nitric acid. The control parameters are etching time and temperature and response parameters are depth of cut and roughness. The etching depth of each specimen was measured by using $0.001 \mathrm{~mm}$ Digital Micrometer. The concentration of etching solution which kept constant which is 40 Baume scale. The depth of cut of selected material is analysed at different control parameters.

The levels of experiments are shown in below Table 1 .
Table 1. Control parameters with levels

\begin{tabular}{|c|c|c|c|}
\hline $\begin{array}{c}\text { Control } \\
\text { parameters }\end{array}$ & Level 1 & Level 2 & Level 3 \\
\hline Temperature $\left({ }^{\circ} \mathrm{C}\right)$ & 43 & 46 & 49 \\
\hline Time (Min) & $10,20,30$ & $10,20,30$ & $10,20,30$ \\
\hline
\end{tabular}

The exposure time was taken $85 \mathrm{sec}$ and the developing time was $90 \mathrm{sec}$. The polymer coating thickness is 4-5 microns.

The experimental results are shown in below table 2 .

Table2. Etching parameters and etching depth relation

\begin{tabular}{|c|c|c|c|c|c|}
\hline $\begin{array}{l}\text { Etching } \\
\text { temperature }\left({ }^{\circ} \mathrm{C}\right)\end{array}$ & Time (Min) & $\begin{array}{l}\text { Etching depth } \\
(\mu \mathrm{m})\end{array}$ & $\begin{array}{c}\text { Surface } \\
\text { roughness }(\mu \mathrm{m})\end{array}$ & $\begin{array}{l}\text { Etching depth } \\
(\mu \mathrm{m})\end{array}$ & $\begin{array}{c}\text { Surface } \\
\text { roughness }(\mu \mathrm{m})\end{array}$ \\
\hline \multicolumn{2}{|c|}{ For both etchant } & \multicolumn{2}{|l|}{ Ferric chloride } & \multicolumn{2}{|l|}{ Nitric acid } \\
\hline \multirow{3}{*}{43} & 10 & 17 & 0.210 & 23 & 0.289 \\
\hline & 20 & 38 & 0.319 & 52 & 0.347 \\
\hline & 30 & 56 & 0.389 & 71 & 0.419 \\
\hline \multirow{4}{*}{46} & 10 & 24 & 0.213 & 34 & 0.301 \\
\hline & 20 & 57 & 0.355 & 76 & 0.398 \\
\hline & 30 & 79 & 0.415 & 109 & 0.495 \\
\hline & 10 & 33 & 0.215 & 45 & 0.311 \\
\hline
\end{tabular}




\begin{tabular}{|l|l|l|l|l|l|}
\hline \multirow{2}{*}{49} & 20 & 71 & 0.388 & 108 & 0.433 \\
\cline { 2 - 6 } & 30 & 106 & 0.502 & 141 & 0.588 \\
\hline
\end{tabular}

\section{RESUlts AND Discussion}

The etching behavior of Stainless-Steel material has been analyzed at different times and temperatures. The preliminary experimentation was performed to study the effect of control parameters on response measures. The depth of etch was recorded at three different points, and average value is calculated for each specimen, the etching depth and surface roughness increases by increasing values of control parameters such as etching temp and time. The energy of etchant molecules increases with temperature and time which results in more etching depth and roughness.

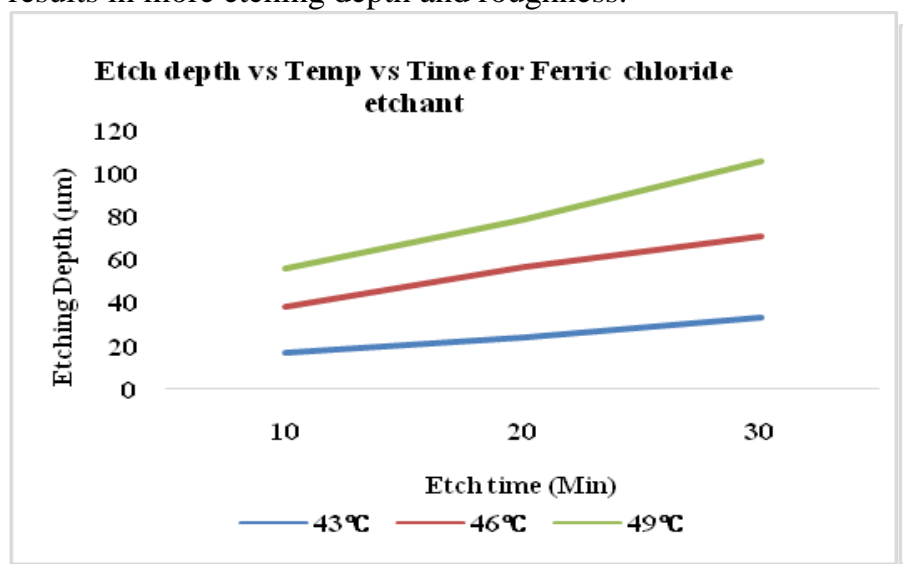

Fig.3Etching temperature v/s etching depth v/s Time for ferric chloride and nitric acid etchant

The control parameters such as etch temperature and time has a significant effect on etching depth and surface roughness on a surface of Steel material. The energy of reaction or collision increases with temperature and time as shown in above figure. In fig. 3 compared control parameters and its effect on etch depth for two different etchants. At $49{ }^{\circ} \mathrm{C}$ etching temperature, the etching molecules are more reactive, which results in more depth of cut. The depth of etching is more for nitric acid etchant due to large numbers of acid molecules (etchant species or ions) are available to etch the base metal. results in more material removal rate.
The values of response parameters are changes by changing the values of control parameters. The below fig. 3 shows the effect of control parameters on response measure.

\section{A. Comparative study of control parameters on depth of etch}

The depth of cut in etching is maximum obtained for nitric acid etchant at $49^{\circ} \mathrm{C}$ i.e., $141 \mu \mathrm{m}$ because the more reaction of etchant molecules on the surface of Stainless Steel. The energy of reactive etchant molecules is more at highest temperature which is $49^{\circ} \mathrm{C}$ compared to other temperatures. As temperature increases the etching reaction is faster and results in more material removal rate.

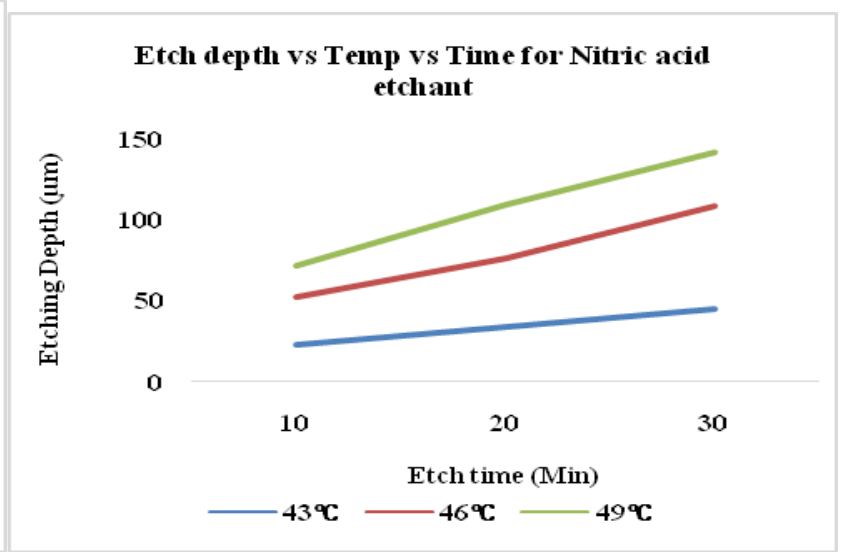

\section{B. Comparative study of control parameters on roughness value}

The depth of cut in etching is maximum obtained for nitric acid etchant at $49^{\circ} \mathrm{C}$ i.e., $0.588 \mu \mathrm{m}$ because the more reaction of etchant molecules on the surface of Stainless Steel. The energy of reactive etchant molecules is more at highest temperature which is $49^{\circ} \mathrm{C}$ compared to other temperatures. As temperature increases the etching reaction is faster and

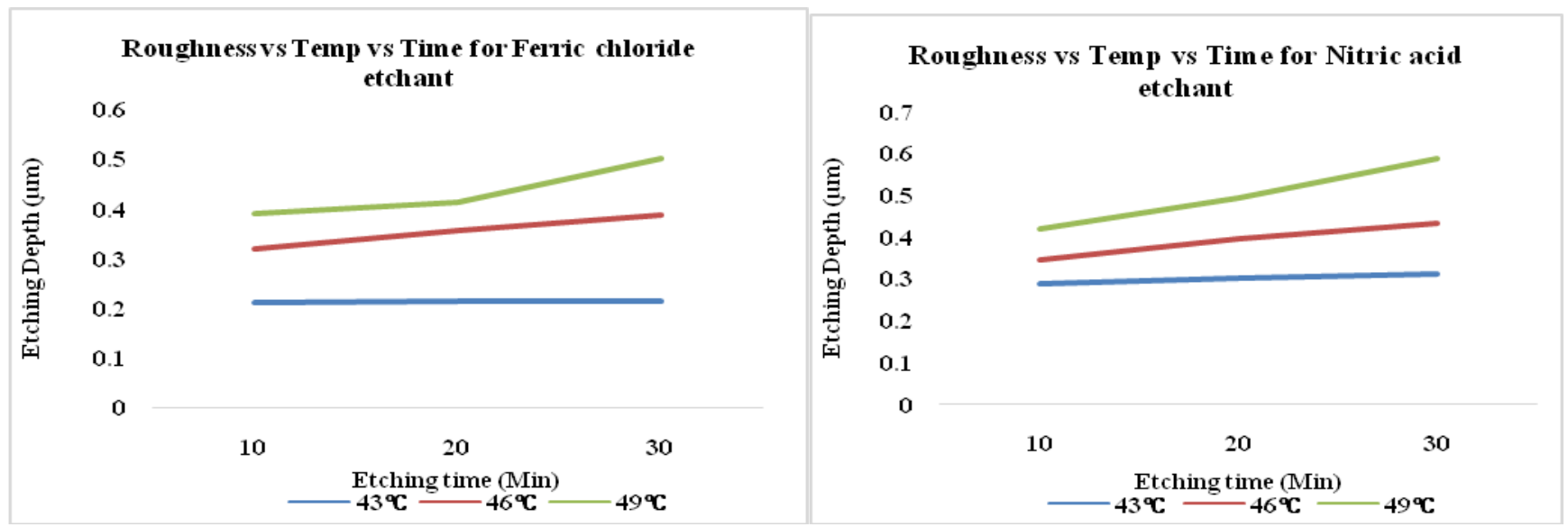

Fig.4 Etching temperature v/s Surface roughness v/s Time for ferric chloride and nitric acid etchant 


\section{Effect of Process Parameters on Etch Depth of Stainless-Steel Material in Photo Chemical Machining by Using Different Etchants}

From above fig 4. It is observed that the value of surface roughness is more nitric acid etched Stainless Steel material due to more etchant molecules colliding onto the surface of steel.

\section{CONCLUSIONS}

In this, the parametric effect of control parameters such as etching time and etching temperature on response parameters has been analyzed. As per experimentation, following conclusions were made.

The energy of reactive etchant molecules is more at highest temperature which is $49^{\circ} \mathrm{C}$ compared to other temperatures. As temperature increases the etching reaction is faster and results in more material removal rate.

- Depth of etching and roughness goes on increasing by increase in temperature and etching time. It is more for nitric acid etched components compared to ferric chloride etched components of Steel.

- The more etching depth obtained for ferric chloride etched components at $49^{\circ} \mathrm{C}$ temperature i.e. 106 microns in 30min. For nitric acid etched components at $49^{\circ} \mathrm{C}$ temperature i.e. 141 microns in $30 \mathrm{~min}$.

- The more value of surface roughness is obtained for ferric chloride etched components at $49^{\circ} \mathrm{C}$ temperature i.e. 0.502 microns in $30 \mathrm{~min}$. For nitric acid etched components at $49^{\circ} \mathrm{C}$ temperature i.e. 0.588 microns in $30 \mathrm{~min}$.

\section{REFERENCES}

[1]Davis, P. J., \&Overturf III, G. E. (1986). Chemical machining as a precision material removal process. precision engineering, 8(2), 67-71.

[2]Allen, D. M., Brightman, J. R. C., Gillbanks, P. J., Smith, P. M., \&Crookall, J. R. (1987). Three-dimensional photochemical machining. CIRP Annals, 36(1), 91-94.

[3] Allen, D. M., \& Almond, H. J. (2004). Characterisation of aqueous ferric chloride etchants used in industrial photochemical machining. Journal of Materials Processing Technology, 149(1-3), 238-245.

[4] Cakir, O. (2006). Copper etching with cupric chloride and regeneration of waste etchant. journal of materials processing technology, 175(1-3), 63-68.

[5]Jang, D. M., Ryu, C., Lee, K. Y., Cho, B. H., Kim, J., Oh, T. S., ... \& Yu, J. (2007, May). Development and evaluation of 3-D SiP with vertically interconnected through silicon vias (TSV). In 2007 Proceedings 57th Electronic Components and Technology Conference (pp. 847-852). IEEE.

[6]Barron, A. R. (2009). Composition and Photochemical Mechanisms of Photoresists. Creative Commons, 1, 1-7.

[7]Bruzzone, A. A. G., \&Reverberi, A. P. (2010). An experimental eval2010uation of an etching simulation model for photochemical machining. CIRP annals, 59(1), 255-258.

[8]Saraf, A. R., Misal, N. D., \&Sadaiah, M. (2012). Mathematical modelling and optimization of photochemical machining. In Advanced Materials Research (Vol. 548, pp. 617-622). Trans Tech Publications Ltd.

[9]Zhang, J., \& Meng, Y. (2012). A study of surface texturing of carbon steel by photochemical machining. Journal of Materials Processing Technology, 212(10), 2133-2140.

[10] Mudigonda, S., \& Patil, D. H. (2015, June). Some investigations on surface texturing on Monel 400 using photochemical machining. In ASME 2015 International Manufacturing Science and Engineering Conference. American Society of Mechanical Engineers Digital Collection

[11] Bhasme, A. B., \& Kadam, M. S. (2016). Experimental investigation of PCM using response surface methodology on SS316L steel. International Journal of Mechanical Engineering and Technology, 7(2), 25-32.

[12] Misal, N. D., \&Sadaiah, M. (2017). Investigation on Surface Roughness of Inconel 718 in Photochemical Machining. Advances in Materials Science and Engineering, 2017.

[13] Misal, N. D., Saraf, A. R., \&Sadaiah, M. (2017). Experimental investigation of surface topography in photochemical machining of Inconel 718. Materials and Manufacturing Processes, 32(15), 1756-1763.

[14] Wangikar, S. S., Patowari, P. K., \&Misra, R. D. (2017). Effect of process parameters and optimization for photochemical machining of brass and german silver. Materials and Manufacturing Processes, 32(15), 1747-1755.

[15] Kamble, B., Utpat, A., Misal, N.D. and Ronge, B.P.,(2019). 3D Photochemical Machining of Copper By using Colored Phototools, International Journal of New Technology and Research (IJNTR) ISSN: 2454-4116, Volume-5, Issue-7, July 2019 Pages 28-32

[16] Wangikar, S. S., Patowari, P. K., \& Misra, R. D. (2016, December). Parametric Optimization for Photochemical Machining of Copper Using Grey Relational Method. In Techno-Societal 2016, International Conference on Advanced Technologies for Societal Applications (pp 933-943). Springer.

[17] Wangikar, S.S., Patowari, P.K., \& Misra, R.D. (2018). Parametric Optimization for Photochemical Machining of Copper using Overall Evaluation Criteria. Materials Today Proceedings. 5(2), 4736-4742, Doi :10.1016/j. matpr.2017.12.046

[18] Wangikar, S. S., Patowari, P. K., Misra, R. D., \&Misal, N. D. (2019) Photochemical Machining: A Less Explored Non-Conventional Machining Process. In Non-Conventional Machining in Modern Manufacturing Systems (pp. 188-201). IGI Global.

[19] Wangikar, S. S., Patowari, P. K., \& Misra, R. D. (2018). Numerical and experimental investigations on the performance of a serpentine microchannel with semicircular obstacles. Microsystem Technologies. 24(8), 3307-3320

[20] Das, S. S., Tilekar, S. D., Wangikar, S. S., \& Patowari, P. K. (2017). Numerical and experimental study of passive fluids mixing in micro-channels of different configurations. Microsystem Technologies, 23(12), 5977-5988.

[21] Chavan, N. V., Bhagwat, R. M., Gaikwad, S. S., Shete, S. S., Kashid, D. T., \& Wangikar, S. S. (2019). Fabrication \& Characterization of Microfeatures on PMMA Using CO2 Laser Machining. International Journal for Trends in Engineering and Technology. 36(1), 39-32.

[22] Kulkarni, H. D., Rasal, A. B., Bidkar, O. H., Mali, V. H., Atkale, S. A., Wangikar, S. S., \& Shinde, A. B. (2019). Fabrication of Micro-Textures on Conical Shape Hydrodynamic Journal Bearing. International Journal for Trends in Engineering and Technology. 36(1), $37-41$.

[23] Raut, M. A., Kale, S. S., Pangavkar, P. V., Shinde, S. J., Wangikar, S. S., Jadhav, S. V., \&Kashid, D. T. (2019) Fabrication of Micro Channel Heat Sink by using Photo Chemical Machining. International Journal of New Technology and Research. 5(4), 72-75.

[24] Patil P. K., Kulkarni A. M., Bansode A. A., Patil M. K., Mulani A. A., Wangikar S. S. (2020) Fabrication of Logos on Copper Material Employing Photochemical Machining. NOVYI MIR Research Journal, 5(6), 70-73.

[25] Wangikar SS, Patowari PK, Misra RD, Gidde RR, Bhosale SB, Parkhe AK (2020) Optimization of photochemical machining process for fabrication of microchannels with obstacles. Materials and Manufacturing Processes, 36:5, 544-557

[26] Bhagwat RM, Gaikwad SS, Shete SS, Chavan NV, Wangikar SS (2020) Study of etchant concentration effect on the edge deviation for photochemical machining of copper. Novyi MIR Res J 5(9):38-44

[27] Kame MM, Sarvagod MV, Namde PA, Makar SC, Jadhav SV, Wangikar SS (2020) Fabrication of microchannels having different obstacles using photo chemical machining process. Novyi MIR Res J 5(6):27-32

[28] Abhay Utpat, N D Misal ,B P Ronge, B A Kamble, "Effect of Process Parameters on Etch Depth of Aluminium Material in Photo Chemical Machining", Advances in Manufacturing Processes, Lecture Notes in Mechanical Engineering. Springer, Singapore, Dec 2020(DOI10.1007/978-981-15-9117-4_7)

[29] A D Sapkal, Abhay Utpat, “ An experimental investigation of Etching depth for Photochemical Machining of Brass", NOVYI MIR Research Journal, Vol 5(9)2020. 